\title{
Mechanical Characterization of Sisal Fiber-Reinforced Recycled HDPE Composites
}

\author{
R. Chianelli-Junior ${ }^{\mathrm{a}}$,J.M.L. Reis ${ }^{\mathrm{b} *}$, J.L. Cardoso ${ }^{\mathrm{a}}$, P.F. Castro ${ }^{\mathrm{a}}$ \\ ${ }^{a}$ Civil Engineering Post Graduate Program - POSCIVIL, Universidade Federal Fluminense - UFF, \\ Rua Passo da Pátria, 156, CEP 24210-240, Niteroi, RJ, Brazil \\ ${ }^{\mathrm{b}}$ Theoretical and Applied Mechanics Laboratory - LMTA, Mechanical Engineering Post Graduate \\ Program - PGMEC, Universidade Federal Fluminense - UFF, Rua Passo da Pátria, 156, \\ CEP 24210-240, Niteroi, RJ, Brazil
}

Received: December 6, 2012; Revised: June 16, 2013

\begin{abstract}
The increasing awareness of the environment protection has contributed to concerns regarding alternative procedures for recycling of plastic wastes. Since chemical processes are high cost, energy and often environment harmful, thermo-mechanical techniques of recycling rises as a good alternative. This research deals with mechanical characterization of thermo-mechanical recycling of composites based on recycled high density polyethylene (HDPE) from post-consumed motor-oil plastic containers as matrix and natural fibers (sisal) as reinforcement. The composites were made by extrusion and then melt blended in a compression mold. The sisal fibers do not contribute to increase tensile strength. As fiber content increases loss of ductility is observed.
\end{abstract}

Keywords: recycling, thermoplastics, composites, mechanical properties

\section{Introduction}

The environmental problem nowadays is a factor of extreme importance in the industrial world, particularly in the case of plastic processing companies, as efforts are mainly focused on the reduction and recycling of wastes generated during transformation processes and also after product end use. Plastics have become one of the materials with the greatest growth in terms of consumption and in the amount of generated wastes ${ }^{1}$.

Although the recycling capacity for plastics has been progressively increased, the fraction of plastics that end up in a landfill is still very significant. The European Union (EU) produced $82.8 \mathrm{Mt}$ of packing waste and $48.1 \mathrm{Mt}$ were recycled ${ }^{2}$. In the United States (US), the total of plastic waste produced in 2008 were $30 \mathrm{Mt}$ and only $7.1 \%$ were recycled ${ }^{3}$. In Brazil, 150kt of waste HDPE are produced per year and only $72 t$ were recycled $d^{4}$. Due to that fact, researchers over the last years have focused their studies in finding ways to reprocess that waste plastics as new products ${ }^{5-10}$.

High-density polyethylene (HDPE) is one of the most widely used polymers, having a broad amount of applications such as bottles, containers and consumer goods. Since post-consumer HDPE from bottles cannot be used again and has high melting viscosity, HDPE becomes an interesting source of recycled material. Recycled HDPE can be used in a growing number of potential applications, such as boxes or pallets, whenever the thermal, mechanical and impact properties of the recycled polymer are close to the ones of the virgin material.

Also, fiber-reinforced thermoplastic composites have emerged as a major class of structural materials, which are characterized by easy processibility, good dimensional

e-mail: jreis@mec.uff.br stability, and excellent mechanical performance. The use of natural fibers as reinforcement in polymers is a way to also recycle these fibers and produce high strength materials. Amongst the advantages of these fibers are: renewable, nonabrasive, cheaper, abundance and show less concern with health and safety during handling and processing.

The mechanical properties of fiber-reinforced composites strongly depend on several factors concerning the fibers, such as size, orientation, dispersion and fibermatrix interfacial bonding ${ }^{11-13}$.

The aim of this work is to investigate the mechanical properties of recycling HDPE from post-consumed motoroil plastic containers reinforced with sisal fibers. The HDPE/ sisal composite were mixed by extrusion and compression molded. Tensile, flexural and thermal tests, TGA and DSC, were performed to evaluate the mechanical properties.

\section{Material and Methods}

\subsection{Material}

Recycled HDPE from post-consumed motor-oil plastic containers were obtained from SEPAN Services (Niterói, RJ, BR). The containers were drained to eliminate any oil residue and then washed with biodegradable soap. The containers were dried at $90^{\circ} \mathrm{C}$ for 3 hours and then shredded into pellets.

Continuous sisal fibers are from the state of Bahia - Brazil and obtained in local stores in matted form. The sisal fibers are extracted from the plant leaf which is a functionally graded composite structure reinforced by three types of fibers: structural, arch, and xylem fibers ${ }^{14}$. The structural 
fibers are located in the periphery of the leaf providing resistance to tensile loads.

Sisal fibers were washed, cut to $30 \mathrm{~mm}$ in length and then oven-dried at $90^{\circ} \mathrm{C}$ for $24 \mathrm{~h}$. All composites were made with $1 \%, 2 \%$ and $4 \%$ in weight of sisal fibers. The sisal fibers were mixed with the polymeric matrix (HDPE) in an extruder screw (Forin, SP, Brazil) with a L:D ratio of $24: 1$. Respective temperatures for the three different processing zones from the hopper to horizontal die of the extruder were set as $170 / 180 / 190^{\circ} \mathrm{C}$ and the screw speed rate was maintained constant at $50 \mathrm{rpm}$. The extruded materials were placed in a molding set at a compression hot press Marconi ${ }^{\circledR} \mathrm{MA} 098 / \mathrm{A}$ at $170^{\circ} \mathrm{C}$ for 5 minutes. The pressure for heating was controlled at $4 \mathrm{t}$ and the cooling pressure was $0.5 \mathrm{t}$. Figure 1 displays the tensile specimens manufacturing process.

\subsection{Methods}

Recycled HDPE thermal behavior was measured with a differential scanning calorimetry, DSC-50H $\mathrm{Shimadzu}^{\circledR}$, under nitrogen atmosphere. DSC samples were heated at a rate of $30^{\circ} \mathrm{C} / \mathrm{min}$ from 10 to $500^{\circ} \mathrm{C}$. The Thermogravimetry (TGA) analysis was performed in the Shimadzu ${ }^{\circledR}$ DTG $-60 \mathrm{H}$, the temperature range from ambient $\left(26^{\circ} \mathrm{C} \pm 2\right)$ to $500^{\circ} \mathrm{C}$, with heating rate of $5^{\circ} \mathrm{C} / \mathrm{min}$. The test was carried out under nitrogen atmosphere at a flow of $50 \mathrm{ml} / \mathrm{min}$.

Sisal fibers were silver covered in an argon vacuum apparatus (Bal-Tec ${ }^{\circledR}$ SDC 005) for $250 \mathrm{~s}$ and then analyzed in a FEI/QUANTA ${ }^{\circledR} 400$ scanning electron microscope (SEM).

Mechanical tests were carried out in an universal-testing machine AG-X 100 Shimadzu $^{\circledR}$ equipped with video type Non-Contact Extensometer elongation measurement. For tensile tests, the ASTM D638 ${ }^{[15]}$ standard was followed. The test speed used was $5 \mathrm{~mm} / \mathrm{min}$ and the distance between grips was $115 \mathrm{~mm}$ for specimens type I. The three-point bending tests were performed according to ASTM D790 ${ }^{[16]}$ at a cross-head displacement of $2 \mathrm{~mm} / \mathrm{min}$ with a support span of $80 \mathrm{~mm}$. Non-contact elongation measurements were performed using CCD cameras to capture digital images of test specimens, see Figure 2. Finally, image processing of the data is carried out on a computer and calculated the elongation of the gauge length.

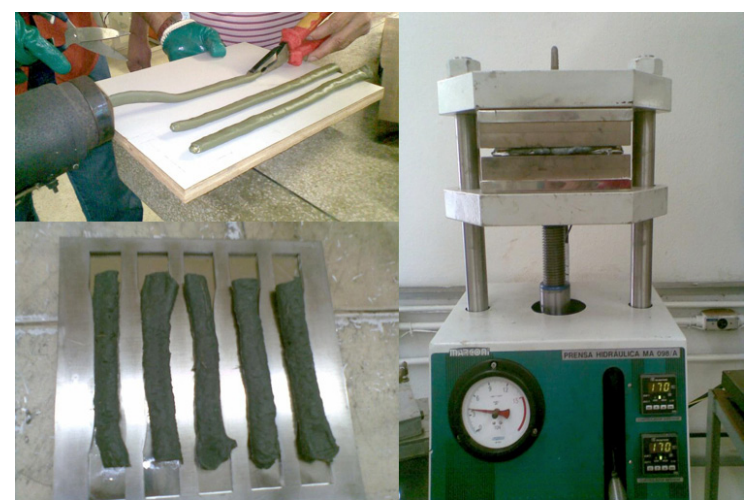

Figure 1. Tensile specimens manufacturing process.

\section{Results and Discussion}

Figure 3 presents the DSC analysis of recycled HDPE.

From Figure 3 it can be seen that recycled HDPE has a melting temperature (TM) of $133^{\circ} \mathrm{C}$. For common commercial grades of medium and high-density polyethylene the melting point is typically in the range 120 to $130^{\circ} \mathrm{C}^{[17]}$. The glass transition temperature $(T g)$ estimates the maximum operating temperature of the composite. In the thermogravimetry analysis is observed the thermal degradation of the composite.

Figure 4 presents the Thermogravimetry (TGA) measurement of recycled HDPE and sisal fibers.

For recycled HDPE, degradation occurred at $430^{\circ} \mathrm{C}$, however, at $200^{\circ} \mathrm{C}$ a slight mass decrease can be observed. This can be explained by the decomposition of the residual oil from the containers.

For sisal fibers, it can be seen that the degradation temperature is $300^{\circ} \mathrm{C}$, higher than the $133^{\circ} \mathrm{C}$ of recycled HDPE TM temperature. Therefore, a composite sisal/HDPE can be processed with no harm to the raw materials.

Sisal fibers microscopies are shown in Figure 5.

The tensile test results from all formulations are presented in Table 1.

Analyzing Table 1 it is clear that sisal fibers has no significant effect in the maximum tensile strength, the standard deviation is less than $3 \%$. Compared to virgin HDPE, the tensile strength of unreinforced recycled HDPE is similar to the values found in the literature ${ }^{8}$. Similar to tensile behavior, the sisal/HDPE flexural strength decreases as sisal fibers are added to the matrix. Incorporating $1 \%$ of

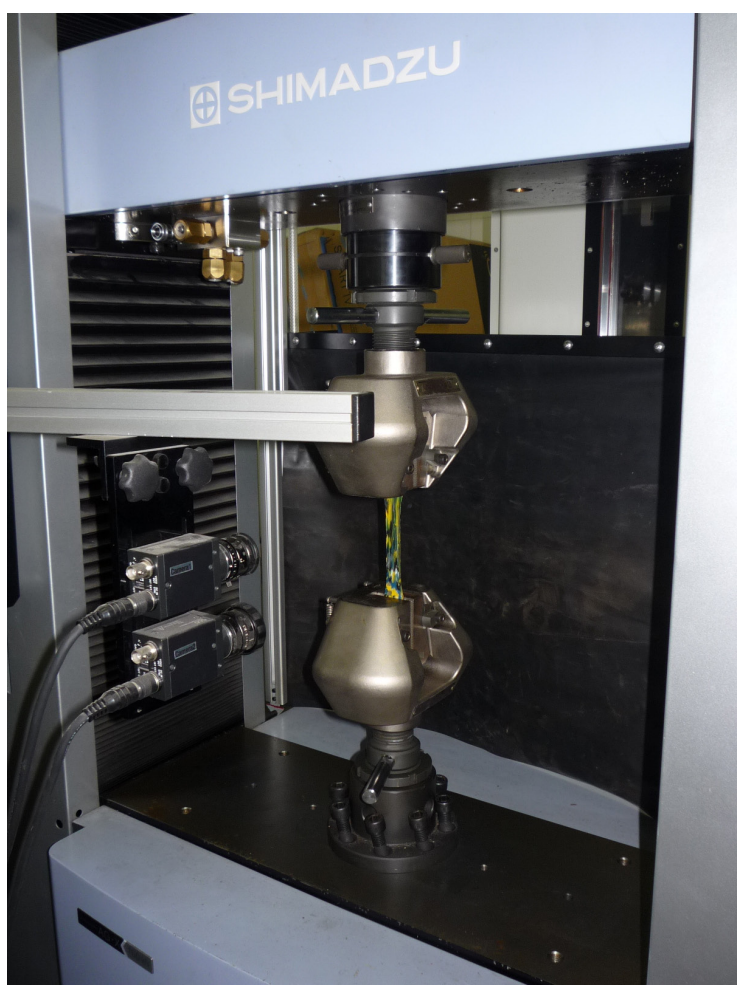

Figure 2. Tensile test set-up using CCD. 


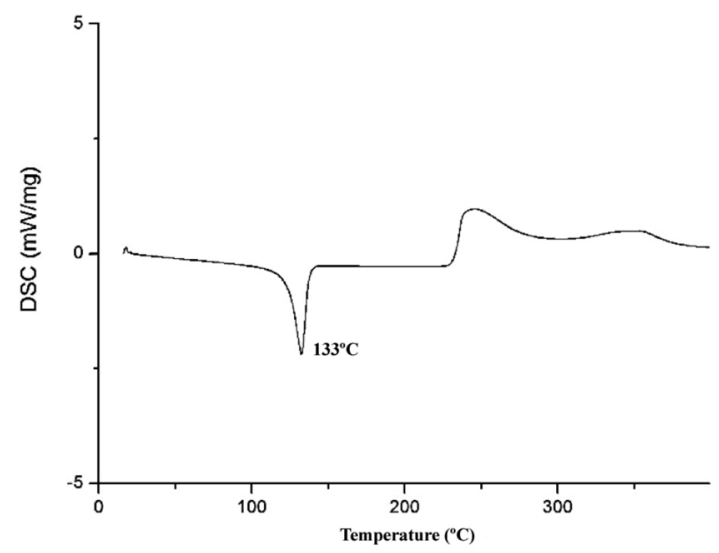

Figure 3. Differential Scanning Calorimetry (DSC) analysis of recycled HDPE.

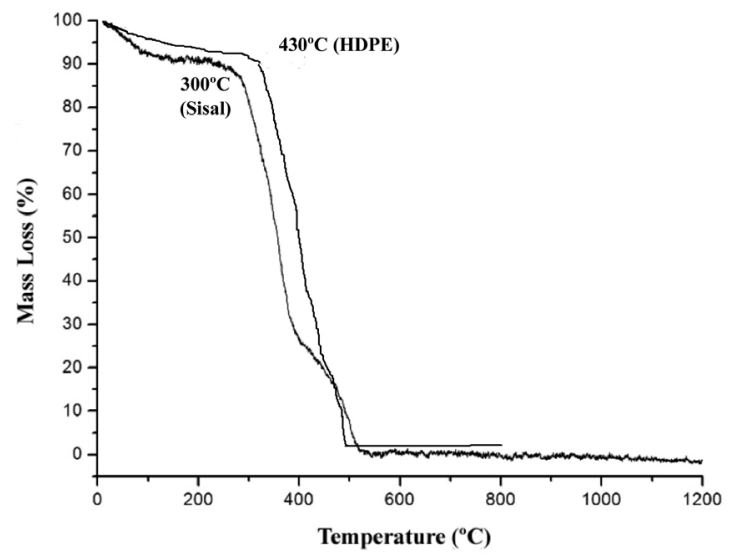

Figure 4. Sisal Fibers and Recycled HDPE TGA test result in nitrogen atmosphere.

sisal fibers diminish the flexural strength in $4.4 \%$. A lower decrease, $1.1 \%$, is observed when $2 \%$ of sisal fibers are used. Increasing sisal fibers content to $4 \%$, the lowest value is calculated, $25.82 \mathrm{MPa}$, representing a $4.9 \%$ decrease. Taking the standard deviation into account, the decrease in the flexural strength of HDPE matrix is not significant. The incorporation of sisal fibers also diminish flexural modulus of elasticity, but again analyzing considering the standard deviation.

Typical tensile stress-strain curves obtained for different sisal fibers content in recycled HDPE matrix are presented in Figure 6.

According to Figure 6 it can be observed that increasing sisal fibers content a loss of ductility in sisal/HDPE composites is reported, but no significant change in the tensile modulus of elasticity is observed. Adding sisal fibers to recycled HDPE matrix contribute to a decrease in the strain. This may be due to a poor fiber/matrix interfacial adhesion, since sisal fibers were used untreated, i.e. with no surface treatment of fibers to improve adhesive bonding. Also, since the recycled HDPE is obtained from oil containers, some residue can contribute to the loss
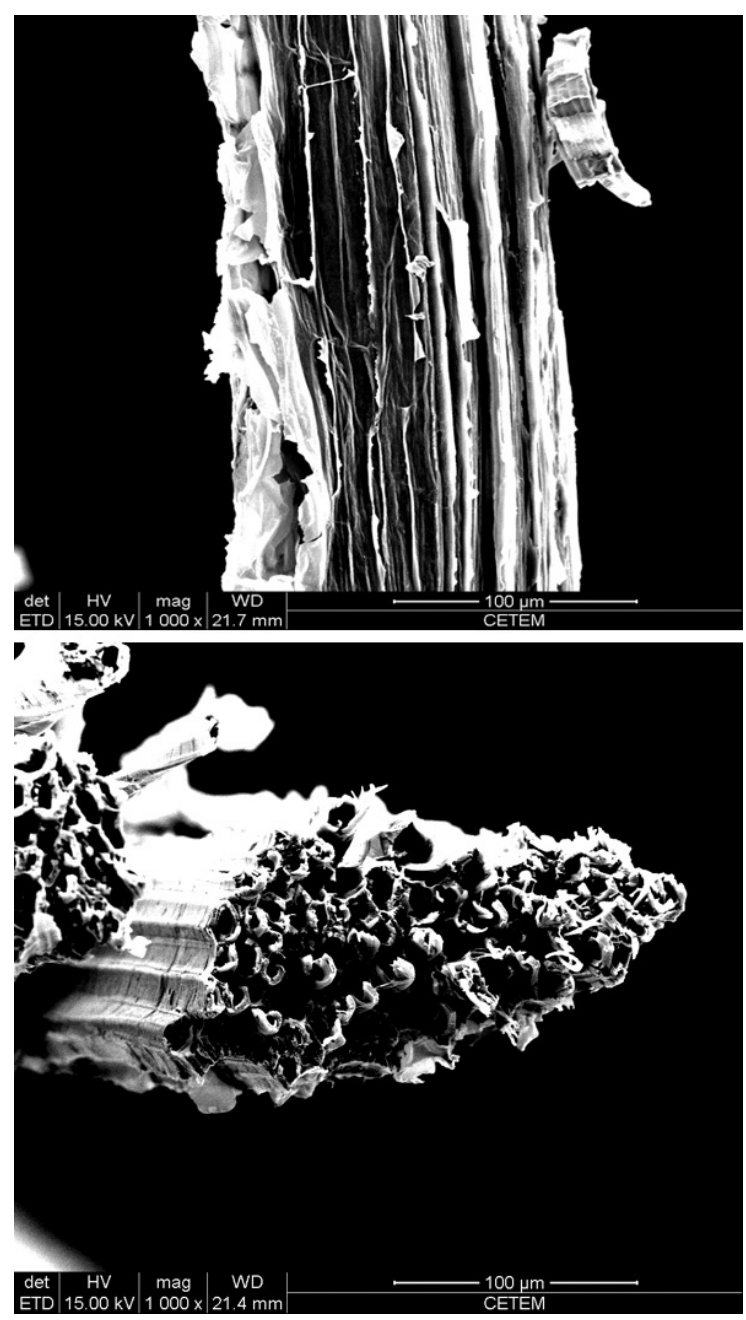

Figure 5. Sisal fiber morphology.

Tensile Sisal/HDPE

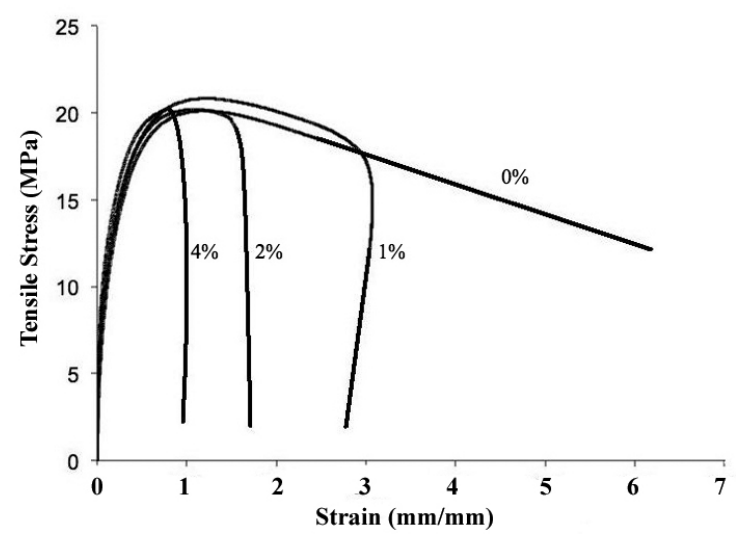

Figure 6. Tensile stress-strain average curves of HDPE/Sisal composites with different fiber percentages.

of ductility. Figure 7 presents the SEM images of the composites containing $4 \%$ of sisal fibers.

From Figure 7 it can be seen that there is a poor fiber/matrix adhesion and in some cases no adhesion is 
Table 1. Tensile strength of all Sisal/HDPE formulations.

\begin{tabular}{cccc}
\hline Fiber \% & Tensile Strength $(\mathbf{M P a})$ & Flexural Strength (MPa) & Flexural Modulus (GPa) \\
\hline 0 & $20.72 \pm 0.5$ & $27.15 \pm 0.8$ & $0.91 \pm 0.02$ \\
1 & $20.66 \pm 0.9$ & $25.94 \pm 1.1$ & $0.83 \pm 0.04$ \\
2 & $20.41 \pm 1.1$ & $26.85 \pm 2.7$ & $0.79 \pm 0.03$ \\
4 & $20.30 \pm 1.0$ & $25.82 \pm 1.6$ & $0.74 \pm 0.07$ \\
\hline
\end{tabular}
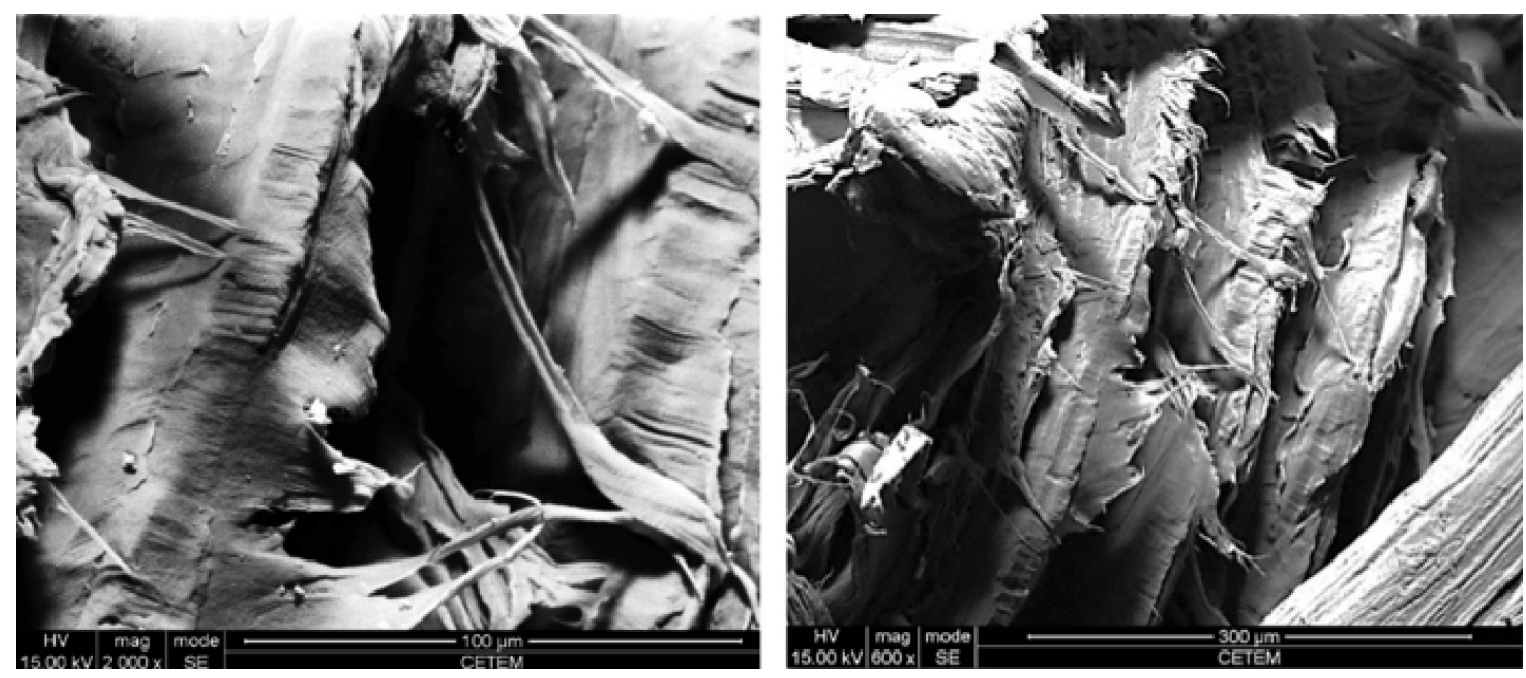

Figure 7. SEM images of the composites containing $4 \%$ of sisal fibers.

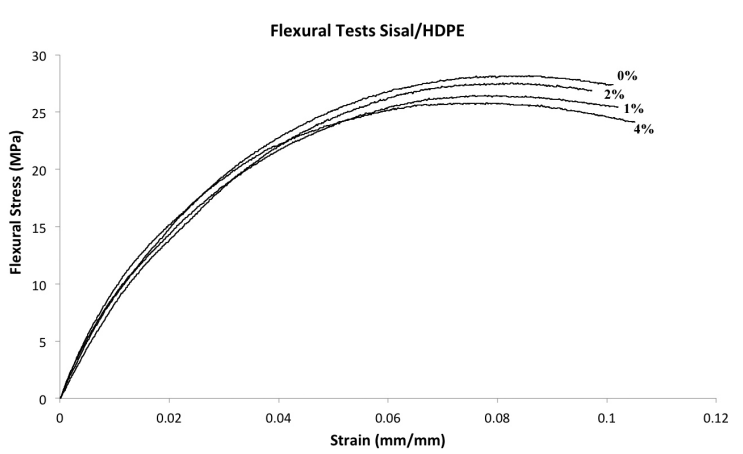

Figure 8. Flexural stress-strain average curves of HDPE/Sisal composites with different fiber percentages.

observed. This poor adhesion can also be explained due to the hydrophilic nature of cellulose and the hydrophobic property of HDPE.

Figure 8 displays the typical curves of flexural strength vs. strain for different sisal fiber content in recycled HDPE matrix.

In flexion, a different post-peak behavior is observed when sisal fibers are added to recycled HDPE matrix. A loss in the maximum flexural strength is observed and $4 \%$ of sisal fibers content provide the higher decrease. The flexural ductility of sisal/HDPE composites are similar to unreinforced recycled HDPE until tests were carried. According to ASTM D790-07[15], the test should be terminated when the maximum strain in the outer surface of the test specimen reaches $0.05 \mathrm{~mm} / \mathrm{mm}$ or at break, if break occurs prior to reaching the maximum strain. Since the maximum strain was reached for all sisal/HDPE at approximately $0.08 \mathrm{~mm} / \mathrm{mm}$ tests were carried out until $0.1 \mathrm{~mm} / \mathrm{mm}$ in order to obtain post-peak behavior and measure maximum flexural strength. No significant change in the flexural modulus of elasticity was observed.

Tensile and flexural behavior of pure HDPE reinforced with sisal fibers is the opposite from recycled HDPE from oil containers reinforced with sisal fibers ${ }^{[5,13]}$. Comparing results, unreinforced HDPE results are slight higher than recycled HDPE. This was expected since the process of heat and cooling degrades thermoplastic materials. Untreated and treated sisal fibers contribute to increase both tensile and flexural properties of virgin HDPE. Recycled HDPE must be completely clean from any substance that can contaminate the post consumer process. In this case the remaining oil, even the one that it cannot be seen, contributes to inhibit a good fiber/matrix surface adhesion.

\section{Conclusions}

The present work showed the usefulness of sisal fiber as reinforcement to recycled high density polyethylene (HDPE) matrix.

The tensile and flexural properties of sisal/recycled HDPE remain the same with no significant detriment to ultimate strength. The interface between sisal fibers and the HDPE matrix is poor due to the hydrophilic nature of cellulose and the hydrophobic property of HDPE. This decrease can be attributed to no fiber surface treatment or oil residue in the matrix. The composites become less ductile 
as sisal fiber content is increased in tension. The modulus of elasticity is unaltered for all sisal fibers percentages. Further work must be done related to fiber surface treatment and residue elimination in recycled HDPE to improve mechanical properties.

\section{References}

1. Sanchez-Soto M, Rossa A, Sanchez AJ and Gamez-Perez J. Blends of HDPE wastes: Study of the properties. Waste Management. 2008;28:2565-2573. PMid:18093819. http:// dx.doi.org/10.1016/j.wasman.2007.10.010

2. European Environmental Agency. The European environment - State and outlook. Copenhagen: European Environment Agency; 2008.

3. Environmental Protection Agency. Municipal Solid Waste in the United States: 2008 Facts and Figures, Washington: European Environment Agency; 2008.

4. Plastivida Instituto Sócio-Ambiental dos Plásticos. Monitoramento dos indices de reciclagem mecânica dos plásticos. São Paulo; 2007. (In Portuguese).

5. Choudhury A. Isothermal crystallization and mechanical behavior of ionomer treated sisal/HDPE composites. Materials Science \& Engineering A. 2008;491:492:500.

6. Sae-Oui P, Sirisinha C, Sanguanthammarong P and Thaptong P. Properties and recyclability of thermoplastic elastomer prepared from natural rubber powder (NRP) and high density polyethylene (HDPE). Polymer Testing. 2010;29:346-351. http://dx.doi.org/10.1016/j.polymertesting.2009.12.010

7. Yemele MCN, Kouba A, Cloutier A, Soulounganga P and Wolcott M. Effect of bark fiber content and size on the mechanical properties of bark/HDPE composites. Composites part: A. 2010;41:131-137. http://dx.doi.org/10.1016/j. compositesa.2009.06.005

8. Adhikary KB, Pang S and Staiger MP. Dimensional stability and mechanical behaviour of wood-plastic composites based on recycled and virgin high-density polyethylene (HDPE). Composites part: B. 2008;39:807-815. http://dx.doi. org/10.1016/j.compositesb.2007.10.005

9. Lei Y, Wu Q, Yao F and Xu Y. Preparation and properties of recycled HDPE/natural fiber composites. Composites

\section{Acknowledgements}

The financial support of FAPERJ (Rio de Janeiro State Funding) and CNPq (Research and Teaching National Council) are gratefully acknowledged.

part: A. 2007;38:1664-1674. http://dx.doi.org/10.1016/j. compositesa.2007.02.001

10. Avila AF and Duarte MV. A mechanical analysis on recycled PET/HDPE composites. Polymer Degradation and Stability. 2003;80:373-382. http://dx.doi.org/10.1016/S01413910(03)00025-9

11. Kim JT and Netravali AN. Mercerization of sisal fibers: Effect o tension on mechanical properties of sisal fiber and fiber-reinforced composites. Composites part: A. 2010;41(9):1245-125. http:// dx.doi.org/10.1016/j.compositesa.2010.05.007

12. Murali Mohan Rao K, Mohana Rao K and Ratna Prasad AV. Fabrication and testing of natural fibre composites: Vakka, sisal, bamboo and banana. Materials and Design. 2010;31(1):508-513. http://dx.doi.org/10.1016/j.matdes.2009.06.023

13. Noorunnisa Khanam P, Abdul Khalil HPS, Ramachandra Reddy G and Venkata Naidu S. Tensile, Flexural and Chemical Resistance Properties of Sisal Fibre Reinforced Polymer Effect of Fibre Surface Treatment. Journal of Polymers and the Environment. 2011;19(1):115-119. http://dx.doi.org/10.1007/ s10924-010-0219-7

14. Li Y, Mai Y-W and Ye L. Sisal Fibre and its composites: a review of recent developments. Composites Science and Technology. 2000;60:2037-2055. http://dx.doi.org/10.1016/ S0266-3538(00)00101-9

15. American Society for Testing and Materials - ASTM. D63808: Standard Test Method for Tensile Properties of Plastics. ASTM; 2008.

16. American Society for Testing and Materials - ASTM. D790-07: Standard Test Methods for Flexural Properties of Unreinforced and Reinforced Plastics and Electrical Insulating Materials. ASTM; 2007.

17. Peacock AJ. Handbook of Polyethylene: Structures: Properties, and Applications. CRC Press; 2000. 